\title{
Flat Adenoma
}

National Cancer Institute

\section{Source}

National Cancer Institute. Flat Adenoma. NCI Thesaurus. Code C65193.

An adenoma of the gastrointestinal tract mucosa which grossly and morphologically does not appear as an elevated or polypoid lesion. 